\title{
Sharing Mechanisms for Information Technology in Developing Countries, Social Capital and Quality of Life
}

\author{
Jeffrey James
}

Accepted: 5 October 2008/Published online: 23 October 2008

(C) The Author(s) 2008. This article is published with open access at Springerlink.com

\begin{abstract}
For the majority of those living in developing countries (especially in the rural areas) sharing may be the only means of obtaining access to IT. Oddly, however, no-one has viewed 'IT for development' specifically from this point of view for the Internet, computers and mobile phones. A good beginning, it seems to me, is to make an analytical classification of existing sharing mechanisms so that they can be compared and contrasted. In so doing I rely partly on the relationship between information technology, social capital and quality of life in developing countries.
\end{abstract}

Keywords Internet · Mobile phones · Computers · Taxonomy · Mismeasurement · Digital divide $\cdot$ Welfare economics $\cdot$ Social capital

\section{Introduction}

Sharing information technology (IT) is not much of an issue in the developed countries since most of the individuals there derive their benefits from the technology via ownership. In the case of mobile phones for example inhabitants of these countries typically have at least one subscription. ${ }^{1}$ In developing countries, by contrast, lower average incomes mean that ownership is limited to a relatively small group of wealthy individuals who live in the modern urban sector. ${ }^{2}$ For the rest of the inhabitants of these countries, therefore, sharing of one kind or another may be the only means of gaining access to and benefitting from IT. So far, however, no-one has looked at 'IT for development' specifically from the standpoint of sharing, though there are already many forms of this type of behaviour. My task accordingly is to fill this rather yawning gap in the literature by providing an analytical

\footnotetext{
1 According to World Bank ICT at-a-glance tables the average percentage of mobile phone subscribers for high-income countries was 90 in 2006.

2 A useful set of case studies dealing with this point is contained in Gillwald (2005).

J. James $(\bowtie)$

Tilburg University, Tilburg, The Netherlands

e-mail: m.j.james@uvt.nl
} 
classification and comparison of the different forms of sharing across the three main types of IT, namely, the Internet, computers and mobile phones. ${ }^{3}$ For part of this task I use the concept of social capital which, according to many people will be increased by IT. According to Quan-Haase and Wellman (2004) for example, the Internet can be regarded as an additional means of communication to facilitate existing social relationships and to follow patterns of civic engagement.

As such, this technology tends to increase existing patterns of social contact and civic engagement. For the World Bank, 'Information technology directly lessens the costs associated with imperfect information. In this way, information has the potential to increase social capital- and in particular bridging social capital which connects actors to resources, relationships and information beyond their immediate environment' (World Bank 2008). In all of these ways the participants will tend to benefit from the increased social capital thus achieved. The World Bank also provides an actual example of how this general mechanism has actually worked in practice. Thus,

Goods can now be sold via the Internet which permits access to greater markets which before could only be reached by those with enough capital to afford transportation. Cooperatives or craftspeople [who share the internet] are beginning to sell their wares to consumers in industrialized countries via the Internet. This typically requires an Internet accessible non-governmental organization (NGO) to act as intermediary between the producers and the consumers ... In this example the internet offers opportunities to enhance social capital among craftspeople within a cooperative and builds bridging social capital by connecting producers and consumers who would otherwise not be able to do business together (World Bank 2008).

Other examples involving the relationship between IT and social capital will be cited below.

\section{The Limits of Ownership-Based Access to Information Technology}

At the heart of my argument in this section lies the important notion of a technological system. According to Stewart (1997),

There are technological linkages between different parts of the system which mean that much of technology comes as a package which cannot be separated and introduced bit-by-bit, but as a package which goes together.

The requirements of a technique extend beyond the material inputs directly involved in the productive process to managerial inputs and infrastructural services. Thus the efficient use of a particular technique ... may impose particular demands for energy, water and transport ... Levels of living of the labour force may be another technical requirement. The required labour input, in terms of energy, concentration, punctuality and literacy are related to the technology ... This is not to argue that each technique imposes a unique set of requirements, and can only be operated if these requirements are met. But any variation tends to lead to variations in the productivity of the techniques, and sufficient deviation from the sort of inputs for which the techniques are designed may lead to a total breakdown. For example, cars designed

\footnotetext{
3 The main goal is not to endorse all the examples that I cite. It is rather to use these as representative of different types of sharing mechanisms.
} 
for advanced - country roads - will not work where there are no roads at all, and the length of life and efficiency of operation will be seriously affected by the different conditions with roads that are not tarmacked and with few mechanics.

Since almost all innovations emanate in and for developed countries they tend to fit in with the characteristics of the technological system in those countries, such as high average incomes, advanced educational attainments and skills, a highly developed infrastructure and so on. In developing countries by contrast only a relatively small part of the economy exhibits the features of this kind of modern technological system. It is typically that part of the economy whose residents live in urban areas and which in other respects approximates the features of a rich-country system. A high percentage of the IT that is adopted by a poor country is concentrated in this so-called 'formal' sector of the dual economy and is used on the basis of individual ownership.

A few examples help to illustrate these points. Consider first the situation with respect to mobile phones (whose relatively low price and lack of user skill requirements make it easier to own than the Internet or computers). According to Donner $(2005$, p. 2) it is true of the poorest countries that 'mobile ownership is still mainly for the privileged middle class and elites in urban areas. For many others, the costs of mobile ownership and use remain prohibitively high'. With respect to the Internet the problem will tend to be even more pronounced, partly because the technology itself is much more expensive and partly because the skills needed to operate this technology are rather formidable (It has long been recognized for example that there is something distinctive about the skill requirements for information technology as against other innovations (van Dijk 2005). And indeed there is clear evidence that recent growth in Internet use has taken place predominantly among members of the formal sector in developing countries. A survey conducted in three African countries for example finds that 'level of education was ... a major factor influencing propensity to use email and internet. Those with secondary and or post-secondary education were far (more) likely to use internet than other educational tiers (Gamos 2003, p. 41).

These privileged groups in developing countries however amount to only a small percentage of the population as a whole and cannot thus long serve as the market for future Internet growth (the exact length of time depends on factors such as the level of per capita incomes the degree of inequality and the speed of adoption in each case). This key point has been made by the authors of a case study on the diffusion of IT in South Africa, when they conclude that' household Internet penetration is concerningly low at $3.5 \%$ of the respondents, with most Internet users acquiring access at work or school. With the low levels of household ownership (12\%) and the high cost of the fixed line infrastructure there is the danger that the internet market will rapidly reach saturation' (Gillwald 2005, p. 250, emphasis added). More generally, it is estimated that in Africa as a whole some $80 \%$ of the population owns neither a mobile or fixed-line telephone.

The problem then becomes the limits to adoption of IT in the so-called 'traditional' technology system which co-exists with its modem counterpart described in the previous paragraphs. The former system is characterized by relatively low levels of technology, skills and infrastructure and it is located mainly in the rural sector of the economy. It is worth emphasizing that much of the production in the traditional technological system is based on non-capitalist modes of production such as non-wage labour where sharing of output is customary. Production units tend to be small-scale and dispersed. ${ }^{4}$ As already

\footnotetext{
${ }^{4}$ For a full description of the technological aspects of the traditional sector see Stewart (1997).
} 
Table 1 The basic classification of sharing mechanisms

\begin{tabular}{lll}
\hline 1. The Internet & 2. Mobile phones & 3. Computers \\
\hline $\begin{array}{l}\text { (a) Users } \\
\begin{array}{l}\text { Inside institution with connection } \\
\text { (eq. telecentres) }\end{array}\end{array}$ & $\begin{array}{c}\text { Family, friends } \\
\begin{array}{l}\text { Sharing a connection outside the } \\
\text { institution }\end{array}\end{array}$ & $\begin{array}{c}\text { Beeping } \\
\text { a remote computer }\end{array}$ \\
$\begin{array}{lll}\text { (b) Non-users } & \text { (b) Commercial } & \text { (b) Individuals benefit as part of } a \\
\text { communal institution }\end{array}$ \\
$\begin{array}{ll}\text { At a distance } & \text { Micro-finance } \\
\text { institutions } & \text { Institutional change in sharing institution }\end{array}$ \\
$\begin{array}{l}\text { Other sharing } \\
\text { institutions }\end{array}$ & $\begin{array}{c}\text { Technical change to promote sharing in } \\
\text { institutions }\end{array}$
\end{tabular}

Source: Partly based on James (2007)

noted there are limits to which IT can be adopted via ownership in the modern sector as well as the traditional sector. Much of the task in gaining future access to IT in developing countries will thus have to be about sharing mechanisms of one kind or another with particular reference to the traditional technology system. In the next section I present a basic classification of sharing mechanisms with reference to the Internet, the computer and the mobile phone. We will have reason to observe that many of the mechanisms described do not appear in calculations of the digital divide or the quality of life in developing countries.

\section{Conceptual Dichotomies and the Basic Classification}

Even in the developed countries there are those who do not own IT and need to rely on some alternative form of sharing access, such as cybercafés, computer rental after school hours and so on. These same mechanisms also exist (mostly in the formal sector) in developing countries. As I will show in this section however many sharing mechanisms are designed to fit in specifically with the traditional technology systems prevailing in the rural sectors of developing countries. The classification scheme presented below thus comprises elements from both modern and traditional technology systems in developing countries. For each type of IT the actual elements in the schema are derived from the use of a conceptual dichotomy and a number of sub-indexes (Table 1). The traditional, as opposed to the modem modern of sharing, are reflected in the dichotomy as well as the subcategories.

Let us first consider how these factors operate in the case of the Internet (shown in column 1 of Table 1).

Table 1 shows that as far as the Internet is concerned the relevant dichotomy is thought to be between users and non-users. Or, in other words, between those with the (many) skills required to operate the technology effectively and those who do not. ${ }^{5}$ The distinction is important because those in the latter category need to be able to benefit from the Internet without actually using it. In developing, as opposed to developed countries, the share of non-users to users is relatively high. It is for this reason that many of the examples below

\footnotetext{
5 van Dijk (2005) has an extensive discussion of the skills required to use the Internet.
} 
Table 2 Percentage schools connected to the internet in a selected sample of countries
Source: World Bank, ICT at-a-glance tables

\begin{tabular}{lr}
\hline Developed countries (2005) & $\%$ \\
\hline Belgium & 93 \\
Japan & 99 \\
Sweden & 99 \\
United Kingdom & 99 \\
USA & 100 \\
\hline Developing countries (2005) & $\%$ \\
\hline Ghana & 1 \\
Malawi & 1 \\
Costa Rica & 15 \\
Trinidad and Tobago & 15 \\
Jamaica & 10 \\
Mongolia & 10 \\
\hline
\end{tabular}

are devoted to sharing mechanisms for non-users of the Internet. This group I should emphasise typically contains individuals with the lowest incomes in developing countries. For, at the one extreme are the richest groups whose incomes enable them to own an Internet-enabled computer. Somewhat less wealthy are the middle to high-middle groups which possess the skills needed to operate the Internet. Because of their relatively advanced user capabilities these groups will tend to earn more than the larger number of individuals without such skills at the lowest levels of the income distribution.

Within the category of users I have made a distinction between sharing that takes place within an Internet-connected institution and the case of sharing a connection by institutions that do not have already one (though they do possess computers). The latter type of sharing is important for example in the case of schools in developing countries, since as shown in Table 2 for a selected group of such countries, the percentage connection to the Internet is rather low as compared with schools in developed countries with perfect or near perfect percentage connections.

As regards non-users of the Internet I have made a further distinction between distance and face-to-face intermediation. In both cases the benefits are derived by the intervention of an intermediary who comes between the technology and the community. But in the one case the intermediation takes place at close range (with rural Internet kiosks for example) and the other at a distance (as in the case of community radio stations that use the Internet for the benefit of their listeners). Either way though sharing of a high-technology, the Internet, takes place very much in the context of a 'low' technology system with limited incomes, skills and infrastructure.

The dichotomy chosen for mobile phones (see Table 1) also reflects a distinction between traditional and modern sharing systems in developing countries. In particular, much of the sharing of this technology in the former system (unlike the latter) takes the form of free use within a household or between friends. This is partly a matter of culture. Many authors speak of a 'culture of sharing in developing countries'. For instance 'the Philippines has a culture in which household members generally share resources' (Pertierra 2005). Or again, in a different context, 'Although a mobile phone may nominally belong to a single person, in some African countries it is regarded as the property of the community, because there is a culture of sharing the tools of communication' (Lopez 2000). 
There is also a greater need to freely share mobile phones within households and between friends in developing countries (more on this below). On the one hand household size tends to be large in developing as opposed to developed countries. Within the former, family size tends to be greater within rural than urban areas, reflecting the traditional aspects of rural areas. Over time in the developed countries household size has fallen from around 5.5 to 2.6 over the past century or so (Bongaarts 2001). By the late nineteen nineties the average for many regions in the developing world was still between 5 and 6 (Bongaarts 2001). On the other hand, large family size often tends to be associated with higher poverty, ${ }^{6}$ thus making it more difficult for individual family members to buy their own mobile phones. Although country-comparative data on sharing mechanisms that do not involve payment are unavailable, household survey data do indicate that many owners lend out their phone on a wide scale. In Botswana, for instance, $62.1 \%$ of the phone owners share this technology with their family, $43.8 \%$ with their friends and $20 \%$ share their phone also with their neighbours (Sebusang et al. 2005).

Note that the term 'non-commercial' also applies whenever users of mobile phones employ the device of 'beeping' one another. For instance, beeping once may mean that the person is at a certain meeting point, whereas beeping twice might signify that there is a half-an-hour delay. However, one beep might also be a signal for saying 'hello'. In these ways using a mobile phone effectively becomes costless. ${ }^{7}$

All other sharing devices for mobiles shown in Table 1 however are commercial in the sense that they have to be paid for, albeit in very small units. I have singled out microfinance based phone services partly because they operate in a different way from other sharing mechanisms and partly because of the unusual degree of success they have enjoyed, primarily in the form of Grameen Telecom. 'As an extension of the original Grameen Bank endeavour to make small group loans to its (female) members, the idea of the Telecom project is to lend money to a Bank member in each village in Bangladesh for the purpose of purchasing a mobile phone. The phone owner then sells call-time to the other villagers, who, it seems, are willing to pay a relatively high proportion of their incomes on this service' (James 2007, p. 290). Note that the intensity of sharing in this project is heightened by the notification of villagers of any incoming calls. This service effectively provides participants with an important element of phone ownership, namely, the ability to receive incoming calls.

The final form of IT considered in Table 1 is the computer which may or may not be used as a component of Internet access. As noted in Table 2 for example relatively few schools in developing countries have an Internet connection in developing countries but many of them will have at least one computer. Using computers in a basic way is more demanding than using a mobile telephone but less exacting than navigating the Internet. The dichotomy I have chosen for computers captures the idea that sharing can take place either by individuals who access a computer at a remote location or by individuals within a sharing location itself. In the latter case there is a sub-division into institutional and technical determinants of the extent to which a computer is actually shared within say a school.

\footnotetext{
${ }^{6}$ Often the causality has to do with economics. For women with relatively high salaries in the developed countries the opportunity cost of having a child is much higher than for a women who is poorly paid or entirely unemployed in a developing country.

${ }^{7}$ For a case study of this phenomenon see Donner (2007).
} 
Fig. 1 Mechanisms for sharing the Internet in developing countries

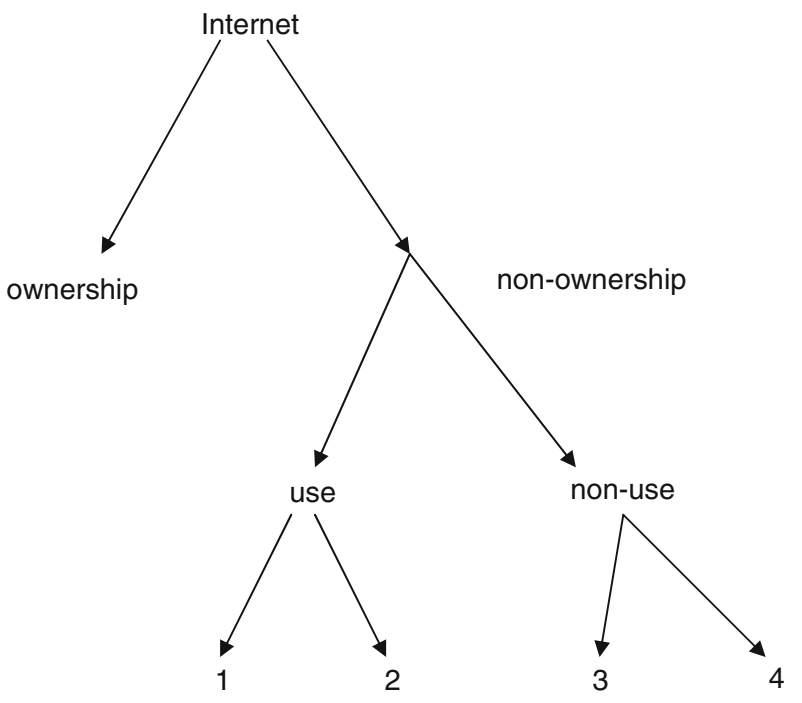

\section{Examples Classified by Category}

As described above Table 1 has yielded numerous categories within which to classify different forms of sharing information technology in developing countries. The purpose of this section is to use these categories to classify actual examples of how IT is shared in the Third World. My hope is that this exercise will provide some analytical structure to what is now just a fragmented list of cases.

\subsection{The Internet}

Because they are relatively numerous it is useful to remind ourselves of the different categories for the Internet by using the tree-diagrammatic form in Fig. 1.

Of the four sharing mechanisms shown in Fig. 1 let me begin with case 1 where benefits are extracted in communal organizations such as telecentres, schools and firms, much as they also are in developed countries. Recall from Table 2 for the case of schools however that the amount of sharing in this category will be proportionally lower in developing than developed countries. Note too that even for those who do engage in sharing the Internet in communal institutions, the actual benefits are likely to be much lower in the former countries. Rural telecentres for example are subject to power cuts, repair and maintenance problems and limited bandwidth (Etta and Wamahiu 2003). Inserting just the modern technology into a traditional technology system usually leads, as noted above, to a much less than desired outcome.

The second category of sharing by users is rather different from the first and more development oriented (with particular reference to rural areas in poor countries). It involves the sharing of an Internet connection by rural institutions that do not already have one and which are prepared to use this technology in non-synchronous ways (that is, in 
cases where some delay is involved in the delivery of information as compared with the real-time alternative used in developed countries). ${ }^{8}$

Consider first in this regard South Africa's 'Wizzy Digital Courier' which was designed specifically for the rural parts of the school system and works even in the many isolated schools that have no telephone line. The system is based instead on the physical movement of data between schools such as these and a location which does have an Internet connection. In particular,

It is a system that involves transporting data saved on a USB memory stick back and forth between one central computer ... and unconnected machines in outlying areas ... Using a program ... designed with open-source software, the school can compose e-mail messages and specify topics for an Internet search. Then it can send a teacher or a gardener off - by bicycle, perhaps - to place the memory stick into a central computer miles away, upload the current batch of communiqués, and retrieve the results of yesterday's requests (James 2008).

By cutting the costs of information in this way, villagers are here benefitting from the increased social capital induced by the introduction of the Internet. The gains accrue in the form of a better education for students.

'DAKNET' is a similar and arguably the most prominent example of non-synchronous Internet connectivity for developing countries. This example has been succinctly described by its founders in the following way.

As an implementation of very low cost asynchronous ICT infrastructure we have developed a store-and-forward wireleness network for rural connectivity...

The DakNet wireless network takes advantage of existing communications and transportation infrastructure to distribute digital connectivity to outlying villages lacking digital communications infrastructure. DakNet combines physical means of transportation with wireless data transfer in order to extend the Internet connectivity provided by a central uplink or Hub (eg. A cybercafé, VSAT, or post office) to kiosks in surrounding villages.

Instead of trying to relay data over a long distance (which can be expensive), DakNet transmits data over short point-to-point links between kiosks and portable storage devices called Mobile Access Points (MAPs). Mounted on and powered by a bus, motorcycle, or even bicycle, the MAP physically transports data ... between kiosks and a Hub (for non-real-time Internet access) ... By employing short-distance radio links, DakNet allows for small low-cost low-power radio devices to be used (Pentland et al. 2004).

It is worth noting at this point that both these examples of rural Internet sharing were specifically designed to fit in with local conditions, not the least of which is that time is a relatively abundant resource which should be used intensively rather than economized upon. ${ }^{9}$ Both cases however are limited to the relatively small number of individuals who

\footnotetext{
8 James (2008) argues that non-synchronous technologies are appropriate for developing countries since they are intensive in time (the abundant resource) and saving in capital (the scarce resource). They buy a lower capital cost by using more of time, which seems perfectly rational. Some examples of non-synchronous technology have been explicitly based on this recognition.

9 For a detailed discussion of this case and its cost compared to other forms of rural communication see Pentland et al. (2004).
} 
can actually operate the Internet effectively. The next category deals with bringing the benefit of this technology to the vast number of individuals lacking these skills (see the second mechanism in Fig. 1).

\section{Non-User Beneficiaries}

As noted above sharing in this subcategory occurs with the help of an intermediary who comes between the Internet and the rural beneficiaries. In the one case intermediation takes place at a distance and in the other at close range. Let me deal first with the former.

It is perhaps best exemplified by a technology 'blending' project in Pondicherry, India, that was designed by the M.S. Swaminathan Research Foundation. What occurs is that ocean wave reports are gathered from the Internet and communicated four times a day to the mostly poor fishermen in the village. Such information helps them to decide whether and when to ply their trade each day. I have referred to this as a case of technological blending because a very recent technology (the Internet) is combined with a much less sophisticated and older technology (namely, the loudspeaker that is used to broadcast the weather forecast to villagers).

Another type of blending occurs when the Internet is combined with radios belonging to some of the poorest groups in rural areas of developing countries. One of the best-known examples of how this type of blend can yield benefits for the local community is the Kothmale Community Radio in Sri Lanka. I am referring here to the way in which this project uses a novel 'radio-browsing' technique to bring together those who transmit information from the Internet and those who receive it. In particular,

The daily programmes respond to queries from listeners. Presenters first select relevant, reliable websites and broadcast the programme with local resource persons as studio guests (e.g. Doctors for a health programme) who discuss the contents of the mostly English-language sites directly in the national languages. They also describe the websites and explain how they are browsing from one page to another. Thus, listeners not only get the information they requested, but they understand how it is made available on the web. They can respond to the programme and they know that essential data will remain available in the community database if they wish to make individual use of it. With this daily radio programme, there is continuity within a common learning process encouraging greater inter-activity with and by the community (Hughes 2003).

Use of the Internet in this case thus enhanced social capital by facilitating more intensive and favourable relationships among those who listen to the radio broadcasts, the presenters and those who appear as voluntary experts on particular topics. The presenters, for example, learned about tea production in other countries and after checking with the experts shared some of the information with his listeners by overcoming market imperfections in gaining knowledge. There were also spontaneous off-the-air relationships between the listeners and the experts that were promoted by the radio broadcasts (such as discussions 'in the street') (Hughes 2003).

It is not clear if Radio Kothmale continues to provide 'Internet-browsing' programmes but very similar models can be found in Nepal and Bolivia. ${ }^{10}$

${ }^{10}$ Note that community radio has the potential to reach hundreds or thousands of people with just one digital connection. As such it stands as a potentially potent way of overcoming the digital divide. 
None of these cases, however, would be relevant if the benefits derived from the Internet by rural residents involve codified transactions of one sort or another, that are determined by specific individual needs. For whereas the distance approach is geared towards general information and a wide audience the face-to-face approach is based on customized transactions of various kinds. This is the reason why so many rural Internet kiosks have emerged to serve the needs of poor, illiterate rural villagers. Many of the services supplied by these kiosks involve documents that need to be obtained from or supplied by local or regional government offices (such as birth and death certificates). Prior to the introduction of the Internet these documents would need to be obtained by long and costly visits to the nearest government offices, involving as they did, standing in long lines and paying bribes along the way. With an Internet connection and an intermediary housed in a rural kiosk, however, these costs of imperfect information can be greatly reduced and social capital increased (in the manner described above by the World Bank).

It is difficult to find a better illustration of how such kiosks can benefit farmers than the 'Bhoomi' project in India.

Bhoomi was launched by the Karnataka state government in order to computerize land records on a massive scale, and to make them available to farmers for a small fee. No fewer than 20 million records have been computerized, and in the form of computerized kiosks, can be securely called up. Such records are crucial to farmers because they are used for other purposes such as loan requests. (James 2005a, b, p. 117, emphasis added)

Other services provided by rural Internet kiosks include help with registration of complaints and submission of applications for issuing certificates and loans. Market price data of agricultural crops in different locations can also be bought for a small fee (I have taken these examples from the 'Gyandoot' project in Madhya Pradesh).

Note that the advantages of an Internet kiosk for rural inhabitants in developing countries can also be delivered by a mobile vehicle as opposed to a fixed stand. In the 'Computers on Wheels' (COW) project in India, for example, mobile 'information providers' use specially equipped motorcycles to travel between villagers. ${ }^{11}$ The cycles are equipped among other things with an Internet-connected laptop computer and are designed to access villages without passable roads. The answers to specific questions posed by villagers are returned once the information provider has established an Internet connection somewhere else. As such therefore this project also falls into the category of nonsynchronous information supply as described above.

Note too that intermediaries, who bring the benefits of the Internet to non-users on a one-to-one basis, need not themselves be located in rural kiosks. Indeed, in the interesting case of 'Babajob.com' in India, what is being sold is the entry on the Internet of a poor jobseeker's profile and this occurs not in rural areas but in a large Indian city. Specifically, the prospective workers dictate their personal data to a secretary who enters them into a computer. Then, once his or her photograph has been taken the resulting profile appears on the Internet. The idea is that matches take place through 'friend of-a-friend' networks (Giridharadas 2007). Imagine for example that two employers are friends and that one of them needs a chauffeur. He can then look up the page of his friend's chauffeur and see which of the chauffeurs' friends are looking for work. In this way 'Babajob' reflects online the underlying process by which hiring decisions are made in real life by Indians: 'using

11 The project is described by the BBC News on 15 July 2002 under the heading 'Villages try out net on wheels' (available at http://www.news.bbc.co.uk/i/hi/sci/tech/2124712.stm). 
chains of personal connections'. The Internet offers another form of conduct for these key relationships, one that may at times be more efficient than the existing alternatives. Either way though the technology would seem to increase the social capital of the community.

\subsection{Mobile Phones}

In spite of the expectations expressed earlier about the likelihood of widespread sharing of mobile phones in (especially poor) developing countries, there are remarkably few data on this topic. Some of the most detailed evidence has been collected by Stork in his field-study of Namibia (2005). What he found was that,

Respondents tend to share their mobiles with family first, friends second and neighbours third. Nearly $30 \%$ of respondents regularly share their mobiles with other family members, compared to about $16 \%$ with friends.

The percentage of respondents that shares their mobiles with family, friends or neighbours is distinguished by household income. One can clearly observe a trend of higher income households tending to share their mobiles less, which can also be attributed to more mobiles being owned per household.

...It can be observed that respondents living in rural areas are more willing to share their mobiles with others than respondents in major urban or other urban areas ... Interestingly, only $2.77 \%$ of respondents that share their mobile phones charge friends, family or neighbours a fee for the use of their cell phones (Stork 2005, pp. 112-113).

A different study by Goodman (2005) specifically studied the impact of mobile phones on social capital in two other African countries, South Africa and Tanzania. He finds that 'In both countries there was a high degree of sharing mobiles for free with friends and family (and sometimes for money). This indicates that mobiles may be acting as a social amenity, a tool to be shared and a focus for social activity, as well as a tool for communications' (Goodman 2005, p. 63). Mobiles were thus enabling people 'to invest in and draw on social capital' (Goodman 2005, p. 66).

If sharing of this kind does not thus seem to be merely a minor phenomenon (at least in these African countries), it is also the case that more people (especially in rural areas) benefit from it than cross-country data on mobile subscribers would suggest. And to this extent the digital divide as conventionally measured will tend to be overstated. The same may hold true for another form of non-commercial sharing known as beeping.

Consider for example the case where the sender is already using some form of communal facility such as a telecentre. He or she may then costlessly beep recipients with a variety of different messages. Donner reports research conducted by a consultancy firm Gamos which concluded that ' $38 \%$ of users of public payphones and telecentres in Uganda, Botswana, and Ghana regularly beeped mobile users from these phones' (Donner 2007). Donner's own research suggests that beeping tends to amplify and strengthen existing relationships and in this way to promote social capital in the relevant communities (2007).

I turn next to the category of sharing mobile phones that was referred to as 'commercial' in Table 1. In the sub-sections of this category a distinction is drawn between microfinance based schemes with particular reference to Grameen Telecom and other sharing arrangements. The case for treating this initiative separately is based on several recognitions. One of them is that Grameen Telecom can be regarded as a pioneer sharing project in 
developing to focus on the creation of micro-enterprises based on IT, but it is also the first such facility to foster village phones on the basis of digital, wireless telephones. As a private rural telecommunications project, Grameen is also a pioneer in targeting poor women in villages as operators (and owners) of the phone. Indeed, social capital in this project is most often discussed in connection with these women who become empowered by owning a phone and become leaders of the community with new ties to its members (Stanley 2005).

But the uniqueness of this project probably rests more heavily on the phenomenal success it has had in the rural areas of Bangladesh and to a lesser extent in Uganda and certain other developing countries. Unlike many other attempts to use IT for the benefit of the rural poor, the effect of Grameen Telecom extends well beyond the level of a village or region. Indeed, data taken from the official site of 'Grameenphone' indicate that 67,000 villages in Bangladesh are affected by the project. If one assumes, as others have done (Cohen 2001), that a single phone covers some 70 rural inhabitants, then no fewer than 45 million villagers in that country have access to a mobile phone, thanks to the Telecom initiative. ${ }^{12}$ Data from the same source suggest that there are some 6.3 million borrowers (village phone operators), $97 \%$ of whom are women. Although it is not known how many of the 45 million villagers with access to a mobile phone actually make use of one, it is clear that the number will run into the tens of millions. It also bears emphasis that whatever this number happens to be it will not be registered under the number of mobile subscribers in international data on Bangladesh. Here too therefore one can talk of an overstatement of the digital divide. Quality of life gains from the project include the difference before and after the introduction of phones. 'The cost of a trip to the city ranges from two to eight times the cost of a single phone call, meaning that the real savings for poor rural people of between $\$ 2.70$ and $\$ 10$ for individual calls' (Stanley 2005, p. 3).

Beyond the Grameen model are sharing initiatives that originate on the supply and demand sides of the transaction. With regard to the former, for example the activities of 'Vodacom' in South Africa bear mention. In particular, that form, as part of its licensing agreement, has generated a Community Service shared access model which resembles an Internet café. Local entrepreneurs re-sell phone time from specially converted containers that are connected to the mobile phone network. This shared-access model is said to account for a significant proportion of mobile calls made within South Africa. In Uganda, local operators act as intermediaries in much the same way as the examples described above in relation to the Internet. The need arises because not even the very limited skills required for using the mobile phone, can always be taken for granted. In some cases for instance potential users are illiterate and require the operator to enter the desired number and confirm it before making the call. Yet another mechanism on the supply side is analogous, to the case of 'computers on wheels' described above in relation to the Internet in India. In particular, in West Bengal rural postmen provide mobile phones at the doorstep of villagers in some 12,000 villages. This scheme is known as 'Grameen Sanchar Sewak' and it was initiated in 2002 by the Indian government (See, for example, http:// www.india.gov/hindi/sectors/communications4php).

On the demand side one example is the pooling of resources to purchase phone time by a peer group of one kind or another. This makes sense when no individual alone can afford to buy the smallest available amount of phone time. By means of pooling resources however the group is able to purchase that minimum amount which may then be loaded onto one individual's phone and shared by all the members. In the same spirit is the case

$\overline{12}$ Grameenphone is available at (http://www.grameenphone.com). 
where people who cannot afford a mobile phone use prepaid cards to make calls from a handset that belongs to someone else. Or again a report on Kenya concludes that 'Phone sharing is also common. Some users just buy a SIM card (which is plugged into the phone to grant access to the network) for less than a dollar and borrow a phone from someone else' (Business Week, Special Report, September 24, 2007). As in the case of South Africa and Tanzania noted above, sharing of phones in Kenya may well also be enabling people to invest in and draw upon social capital.

\subsection{Computers}

I have already referred to cases where the Internet has been 'blended' with more traditional forms of technology such as radios and loudspeakers. As we now turn to the last form of IT, computers, another form of blending comes immediately to the fore. In terms of Table 1 it falls under the category where individuals benefit from access to a remote computer (as will become apparent this case, like the previous examples of blending, demonstrates that sharing IT is a serious means of reaching the groups with the least access to this form of technology).

I am referring specifically to 'Kisan Call Centres' in India which operate on the basis of combining telephones and computers and were initiated by the Department of Agriculture in 2004. ${ }^{13}$ The project represents a novel application of IT to extension services in that country. With a national toll-free number any farmer, literate or not, can call the Center which is staffed by someone with an agricultural degree and is proficient in the local language (calls from within a given state are answered from a call centre located in that state). Such a person is the first to deal with an incoming call and enters information about the caller and the query into a computer. If the query cannot be answered at this level it is referred by computer to a specialist in the area. Data collected in the computers from registration of caller queries are used as inputs to an information base. Kisan makes particular sense in a country like India with a relatively large number of public payphones. As yet however no data are available to measure the extent to which the centres are actually being used. What we do know is that the government plans to double the number of call centres from 14 to 28 .

The remaining examples under the category of sharing computers occur within a communal institution rather than between an individual and a remote computer. I have drawn a distinction among these remaining examples between increased sharing that results from some kind of institutional change as opposed to a technological innovation. A school for example undergoes an institutional change when it allows its computers to be used by community members outside of regular hours. This is what occurred in a 'World Links, ${ }^{14}$ project in Uganda where an after-school community telecentre project was developed (Best and McClay 2001). 'Under this program, schools in rural Uganda that are equipped with computer labs and VSAT-based Internet connections are opening up their labs to outside clients in the afternoon and evenings on a cost-recovery basis' (Best and McClay 2001, p. 81). 'World Links' continues to apply this basic model in a variety of other developing countries such as Zimbabwe, India and Brazil. Extended, use of the internet has of course the potential to increase social capital as noted above.

\footnotetext{
13 'Kisan Call Center' (available at http://www.manage.gov.in/kisan/default.htm).

14 The homepage of 'World Links' is available at http://www.world-links.org.
} 
MIT's one-laptop-per-child programme $(\mathrm{OLPC})^{15}$ also represents an institutional change in that it seeks to drastically alter the existing number of children per computer in developing countries. Indeed, as its name suggests, the programme seeks to deliver a (lowcost) laptop to each and every child at school. One would have thought that so extreme an objective-of effectively precluding sharing in schools-was well justified by its promoters. Yet quite the opposite is the case and the objective is scarcely defended at all, which is the more problematic because it runs directly counter to any notion of appropriate technology in developing countries. ${ }^{16}$ This well-established idea turns on the idea that developing countries cannot afford the standards set in the rich part of the world and have therefore to set lower standards to incorporate more than a small percentage of the population. ${ }^{17}$ Since the number of students per computer that is thought to be pedagogically effective in developed countries is thought to be 4-5 (US Department of Education 2001), the OLPC is effectively setting an even more stringent rule. Not surprisingly the application of this rule would severely imbalance the education budget in developing countries. Peru, for example, is said to be currently spending on laptops nearly a third of the education budget normally available for capital expenditures (Talbot 2008).

Regardless of whether each child does receive a laptop, however, the OLPC product does embody a desirable technological feature that promotes sharing within a school and as such exemplifies the sub-category devoted to these forms of innovation in Table 1 . In particular,

Using standard wireless protocols, the laptops are automatically able to form a "mesh network" where each machine acts as both laptop and router, able to pass information between computers.

If one laptop is switched on in range of an internet connection ... all other laptops on the network can share the access .... If there is no Internet access, the laptops can still share data, video and information through the mesh (BBC 2007).

No less interesting are the attempts to use multiple mice in schools in developing countries. The idea began with the familiar observation that in India there are insufficient computers in relation to the number of students. The result is that only the child with access to the mouse benefits from use of the computer (or at least the benefits of users exceed those of non-users of the mouse). The latter sometimes vye for control of the mouse and gradually lose interest and begin doing something else (Pawar et al. 2006). One way to overcome this problem, according to Pawar et al. (2006) is to provide each child with a mouse and cursor on the screen. Initial trials to develop software with these properties culminated in a Windows product called 'Multipoint'. ${ }^{18}$ This software allows a single computer to connect with multiple mice, each of which belongs to an individual student. Thus instead of giving each student an entire computer (as in the OLPC programme), this approach gives students the chance to share a single computer.

\footnotetext{
15 The homepage of OLPC is http://www.laptop.org/.

16 On the concept and application of appropriate technology see Stewart (1997).

17 If for example housing standards were set at developed countries the vast majority of the population would be excluded. What are needed are intermediate standards, that lie somewhere between having no standards and developed country levels.

${ }^{18}$ For a description of the product see http://www.research.microsoft.com/users/udaip/multipoint.htm.
} 


\section{Conclusions}

I began this paper by discussing the relationship between IT, social capital and quality of life in developing countries. I took note of the considerable potential that IT has for increasing the social capital among communities and thus for improving the quality of life for the inhabitants. The Internet for example can be regarded as an additional means of communication to facilitate existing social relations and to follow patterns of civic engagement. IT also has the ability to reduce the costs associated with imperfect information and hence the ability to intensify social relationships beyond the level that would otherwise be the case. An example involving the use of IT to increase trade among a group of artisans shows that the connection between IT and social capital does actually occur in developing countries.

I then suggested that the institution of ownership which dominates the modes of access to IT in developed countries will not get us far in providing access to IT in the rural sector of developing countries. It was emphasized that sharing provides the only viable alternative to individual ownership in this context. As yet however no one has looked at IT specifically from the standpoint of sharing. The existing examples remain unrelated to one another and this fragmentation does not well serve those who want to see a more structured classification of the examples that do exist. Distilled from the examples in the text, Table 3 hopefully fills part of this gap for the Internet, mobile phones and computers.

Several aspects of Table 3 bear emphasis. One of them is that most of the examples cited therein originate in and for developing countries. They tend to exhibit properties that are different from what is found in developed countries (although a few examples are

Table 3 A summary of sharing mechanisms

\begin{tabular}{|c|c|c|}
\hline 1. The Internet & 2. Mobile phones & 3. Computers \\
\hline (a) Users & (a) Non-commercial & $\begin{array}{l}\text { (a) Individuals benefit from sharing a } \\
\text { remote computer }\end{array}$ \\
\hline $\begin{array}{l}\text { Inside institution with } \\
\text { connection (telecentres, } \\
\text { schools) }\end{array}$ & Family, friends (Namibia case study) & $\begin{array}{l}\text { Kisan Call Centres, as blending } \\
\text { computers and telephones }\end{array}$ \\
\hline $\begin{array}{l}\text { Sharing a connection } \\
\text { outside the institution } \\
\text { (Wizzy Digital Courier; } \\
\text { Daknet) }\end{array}$ & $\begin{array}{l}\text { Beaping (regular occurrence in } \\
\text { Uganda, Botswana and Ghana) }\end{array}$ & \\
\hline (b) Non-Users & (b) Commercial & $\begin{array}{l}\text { (b) Individuals benefit as part of a } \\
\text { communal institution }\end{array}$ \\
\hline $\begin{array}{l}\text { At a distance (blending } \\
\text { project in Pondicherry; } \\
\text { community radio in } \\
\text { Sri Lanka }\end{array}$ & $\begin{array}{l}\text { Micro-finance institutions (Grameen } \\
\text { Telecom) }\end{array}$ & $\begin{array}{l}\text { Institutional change in sharing } \\
\text { computers (using computers by } \\
\text { community outside regular school } \\
\text { hours; OLPC) }\end{array}$ \\
\hline $\begin{array}{l}\text { Close range (rural Internet } \\
\text { Kiosks such as Bhoomi } \\
\text { and Gyandoot }\end{array}$ & $\begin{array}{l}\text { Other sharing institutions (Vodacom } \\
\text { in South Africa; local } \\
\text { intermediaries in Uganda; pooling } \\
\text { resources; SIM card; mobile phones } \\
\text { delivered to the doorstep of } \\
\text { villagers in India }\end{array}$ & $\begin{array}{l}\text { Technical change to promote sharing } \\
\text { in institutions (OLPC; multiple } \\
\text { mouse) }\end{array}$ \\
\hline \multicolumn{3}{|l|}{$\begin{array}{l}\text { Computers on Wheels } \\
\text { (COW) }\end{array}$} \\
\hline Babajob.com & & \\
\hline
\end{tabular}


common to both parts of the world). Policy needs to figure out whether these indigenous innovations are cost-effective and if so how to replicate them (as has already been done for the case of Grameen Telecom). Relatedly, we need to recognize that several important instances of sharing go unrecorded in official cross-country data and to this extent the digital divide between rich and poor countries is overstated. Finally, I have suggested that the much-vaunted OLPC project is unrealistic and wasteful because the recommended number of students per computer in developed countries is only 4 or 5, not one-to-one. Spending an amount greater than would be required for 4-5 students can properly be regarded as unnecessary. The whole point of the appropriate technology idea is that developing countries need not adopt the same standard as the developed world, so even the goal of 4-5 students per computer is highly questionable. Something like 10-12 students per computer probably makes much more sense.

Open Access This article is distributed under the terms of the Creative Commons Attribution Noncommercial License which permits any noncommercial use, distribution, and reproduction in any medium, provided the original author(s) and source are credited.

\section{References}

BBC. (2007, July 23). Factfile: XO laptop.

Best, M., \& McClay, C. (2001). Community access in rural areas: Solving the sustainability puzzle. The Global Information Technology Report, 2001-2.

Bongaarts, J. (2001). Fertility and reproductive preferences in post-transitional societies. In R. Bulatao \& J. Casterline (Eds.), Global fertility transition. New York: Population Council.

Cohen, N. (2001). What works: Grameen telecom's village phones. World Resources Institute, Digital Dividend. Available at http://digitaldividend.org/pdf/grameen.pdf.

Donner, J. (2005). Research approaches to mobile use of the developing world: A review of the literature. Paper Presented at Conference on Mobile Communication and Asian Modernities, City University of Hong Kong, June 7-8. Available at http://www.jonathandonner.com/donner-mobrev.pdf.

Donner, J. (2007). The rules of beeping: Exchanging messages via international "missed calls" on mobile phones. Journal of Computer-Mediated Communication, 13(1).

Etta, F., \& Wamahiu, S. (2003). Information and communication technologies for development. Senegal: Codesria, IDRC.

Gamos Ltd. (2003). Innovative Demand Models for Telecommunications. Available at http:// www.teleafrica.org/pdfs/FinalReport.pdf.

Gillwald, A. (Ed.). (2005). Towards an African e-index: ICT access and usage. Johannesburg, South Africa: The Link Centre, Wits University School of Public and Development Management.

Giridharadas, A. (2007, October 30). Poverty inspires technology workers to Altruism. New York Times.

Goodman, J. (2005). Linking mobile phone ownership and use to social capital in rural South Africa and Tanzania. Vodafone Policy Papers, No. 2.

Hughes, S. (2003). Community multimedia centres: Creating digital opportunities for all. In B. Girard (Ed.), The one to watch: Radio. FAO, Rome: New ICTs and Interactivity.

James, J. (2005a). Technological blending in the age of the internet: A developing country perspective. Telecommunications Policy, 29(4). doi:10.1016/j.telpol.2004.11.010.

James, J. (2005b). The global digital divide in the internet: Developed country concepts and third world realities. Journal of Information Science, 31(2). doi:10.1177/0165551505050788.

James, J. (2007). From origins to implications: Key aspects in the debate over the digital divide. Journal of Information Technology, 22, 284-295.

James, J. (2008). Time-intensive information technology and human welfare in developing countries. Prometheus (forthcoming).

Lopez, A. (2000, July-August). The south goes mobile. UNESCO Courier.

Pawar, U., Pal, J., \& Toyama, K. (2006). Multiple mice for computers in education in developing countries. In IEEE/ACM International Conference on Information and Communication Technologies for Development, ICTD. 
Pentland, A., Hassan, A., \& Fletcher, R. (2004). DakNet: Rethinking connectivity in developing nations. IEEE Computers, 37(1), 4-9.

Pertierra, R. (2005). Mobile phones, identity and discursive intimacy. Human Technology, 1(1), 23-44.

Quan-Haase, A., \& Wellman, B. (2004). How does the internet affect social capital? In M. Huysman \& V. Wulf (Eds.), Social capital and information technology. Cambridge: MIT Press.

Sebusang, S., Masupe, S., \& Chumai, J. (2005). Botswana. In A. Gillwald (Ed.), Towards and African eindex: ECT access and usage. Johannesburg, South Africa: The Link Centre, Wits University School of Public and Development Management.

Stanley, R. (2005). Village phone-a tool for empowerment. Grameen Foundation, USA Publication Series. Stewart, F. (1997). Technology and underdevelopment. London: Macmillan.

Stork, C. (2005). Namibia. In A. Gillwald (Ed.), Towards and African e-index: ECT access and usage. Johannesburg, South Africa: The Link Centre, Wits University School of Public and Development Management.

Talbot, D. (2008, May 16). OLPC laptop gets windows. Technology Review.

US Department of Education. (2001, Fall). Internet Access in US Schools.

van Dijk, J. (2005). The deepening divide. London: Sage.

World Bank. (2008). Social capital and information technology. Available at http://web.worldbank.org/ WBSITE/EXTERNAL/TOPICS/EXTSOCIALDEVELOPMENT. 